\title{
ANALISIS MANAJEMEN RISIKO TEKNOLOGI INFORMASI PADA PERUSAHAAN TOKO UJUNG PANDANG GROSIR PENAJAM PASER UTARA MENGGUNAKAN FRAMEWORK ISO 31000:2018
}

\author{
Joy Nashar Utamajaya $\mathbb{( i D}^{1)}$, Afrina $\mathbb{( i )}^{2)}$, dan Anisa Nur Fitriah $\left(\mathbb{B}^{3)}\right.$ \\ ${ }^{1,2,3}$ Sistem Informasi, STMIK Borneo Internasional Balikpapan \\ ${ }^{1,2,3}$ Jl. AW.Syahranie No.04, RT.32, Batu Ampar, Kec.Balikpapan Utara,Kota Balikpapan, Kalimantan Timur 26136 \\ E-mail : joy.nashar@stmik-borneo.ac.id ${ }^{1)}$,Afrina.18@stmik-borneo.ac.id ${ }^{2}$, Anisa_nur_fitriah.18@stmik-borneo.ac.id ${ }^{3)}$
}

\begin{abstract}
ABSTRAK
Toko grosir ujung pandang penajam paser utara merupakan sebuah perusahaan yang bergerak dalam bidang penjualan sembako, toko tersebut sudah menggunakan penerapan Teknologi Informasi dalam menunjang aktivitas bisnis yang dijalankan. Toko tersebut menggunakan website yang digunakan untuk menunjang penjualan, mendata stok barang, serta mendata pengeluaran sehari-hari yang dibutuhkan. Namun dalam dunia manajemen pasti selalu ada kemungkinan risiko yang mungkin dapat terjadi dan dapat mengganggu aktivitas bisnis dalam penggunaan sistem tersebut. Adapun tujuan dari penelitian ini untuk menganalisis risiko yang sangat diperlukan yang terhadap sumber daya Teknologi Informasi yang terdapat pada toko tersebut dengan menggunakan ISO 31000 diharapkan dapat meminimalisasi risiko yang terdapat pada website. Peneliti ini menggunakan metode penelitian Case Study Research dengan pendekatan kualitatif yaitu pendekatan yang dilakukan dengan mendeskripsikan atau menguraikan data dan fakta yang terjadi di dalam objek studi kasus kedalam bentuk kata-kata. Adapun hasil dari analisis risiko ini berupa analisis kemungkinan risiko, mengelompokkan kemungkinan risiko berdasarkan dampak nya sehingga menghasilkan usulan tindakan risiko terhadap kemungkinan risiko yang terdapat pada website, dengan begitu toko tersebut dapat memperlakukan kemungkinan risiko yang ada sesuai dengan prioritas level risikonya dan dapat mencegah serta meminimalisasi sehinga tidak mengganggu aktivitas bisnis di Toko ujung pandang grosir penajam paser utara.
\end{abstract}

Kata Kunci: Risiko, ISO 31000, Website, Teknologi Informasi

\section{PENDAhuluan}

Peranan teknologi pada aktivitas manusia pada saat ini memang begitu besar. Hampir semua organisasi telah membuka mata dengan memberikan perhatian terhadap perkembangan teknologi khususnya teknologi informasi (Pramanda, dkk, 2016). Dalam teknologi informasi seperti ini kemudahan dalam berbagi informasi ataupun mencari informasi sangatlah penting dapat dilihat dari semakin berkembangnya teknologi internet dan jaringan. Sekarang ini internet merupakan suatu kebutuhan dalam berbagi informasi ataupun mencari informasi (Naibaho, 2017)

Pengelolaan Sistem informasi di suatu perusahaan memang penting begitu pula dengan Toko Ujung Pandang Grosir, toko sembako yang sudah mengoptimalkan pengelolaan Teknologi Informasi di setiap aktivitas manajemen perusahaan nya, hal ini dapat dibuktikan dengan adanya website. Namun tidak dapat di pungkiri walaupun pengelolaan sistem informasi Toko ujung pandang grosir penajam sudah optimal, pasti memiliki beberapa kemungkinan ancaman dan risiko yang dapat mengganggu aktivitas proses bisnis yang berjalan terutama masih dapat dilihat secara visual dengan jelas terdapat beberapa risiko di perusahaan toko ujung pandang grosir penajam yang belum mendapatkan perlakuan risiko seperti Human Error, Overheat, dan Server Down sehingga diperlukan analisis dan evaluasi manajemen risiko terhadap Toko ujung pandang grosir penajam dengan mengidentifikasi kemungkinan risiko dan potensial risiko yang ada, seberapa besar dampak dari risiko yang mungkin terjadi, penilaian dan evaluasi risiko serta apa yang harus dilakukan untuk mengantisipasi risiko dan permasalahan yang ada. Oleh karena itu diperlukan tindakan untuk mengelola risiko yang ada, tindakan mengelola risiko ini telah diatur dalam ISO 31000:2018 Tentang risk management, manajemen risiko adalah upaya manajemen untuk mengendalikan risiko kegiatan operasional perusahaan dengan melakukan analisis risiko, evaluasi risiko dan rencana mitigasi nya (Adi \& Susanto, 2017)

Dalam hal ini tentang analisis risiko teknologi informasi website toko ujung pandang grosir penajam ini dengan pendekatan menggunakan metode ISO 31000:2018. Pada bulan Februari 2018, Organisasi Standar Nasional (ISO) memperkenalkan ISO 31000:2018 kepada public. ISO ini berisikan mengenai Standar Manajemen Risiko. Dengan diterbitkannya ISO 31000 versi terbaru ini maka diharapkan dapat menggantikan standar yang banyak berbeda yang saat ini banyak digunakan perusahaan. ISO 31000:2018 
merupakan pedoman standar, instruksi, dan tuntutan bagi sebuah organisasi atau perusahaan untuk membangun sebuah fondasi dan kerangka kerja bagi suatu program manajemen risiko. Fondasi tersebut meliputi aturan, tujuan, dan komitmen untuk membangun suatu program manajemen risiko yang komprehensif. Kerangka kerja meliputi perencanaan, akuntabilitas dari para karyawan, proses dan aktivitas yang digunakan untuk mengelola risiko dalam kinerja perusahaan. Untuk mengelola risiko di Toko ujung pandang grosir penajam ini diperlukan risk assessment yang diatur dalam ISO 31000:2018 Analisis risiko menggunakan ISO 31000:2018 dapat terlihat risk value atau nilai risiko dengan tiga tingkatan yaitu risiko dengan tingkatan rendah, sedang, dan tinggi (Angraini \& Pertiwi, 2017)

Dengan fakta yang menunjukkan pentingnya dilakukan analisis manajemen risiko teknologi informasi perusahaan toko ujung pandang grosir menggunakan metode ISO 31000:2018 dimana standar dari metode ini memiliki pandangan yang lebih luas dan dapat diterapkan di berbagai ruang lingkup organisasi serta lebih konseptual dibandingkan standar lain nya (Ramadhan, dkk., 2020). Fokus dari metode penelitian ini adalah untuk melakukan identifikasi dari beberapa aset teknologi informasi di Toko Ujung Pandang Grosir Penajam dan mengidentifikasi kemungkinan risiko yang ada, berapa besar dampak yang ditimbulkan risiko tersebut, serta memberikan rekomendasi kepada Toko Ujung Pandang Grosir Penajam terhadap risiko-risiko yang ada maupun risiko-risiko yang sewaktu-waktu bisa muncul. Dengan begitu kinerja dari aktivitas Teknologi Informasi maupun proses bisnis di toko ujung padang grosir penajam paser utara dapat lebih dioptimalkan oleh pihak organisasi atau perusahaan. Dalam dunia Manajemen, setiap hal yang dijalankan dalam suatu organisasi atau perusahaan pasti selalu diiringi dengan ancaman dan risiko. Risiko selalu membayangi setiap kegiatan yang dijalani untuk menghambat organisasi atau perusahaan untuk mencapai tujuan maupun visi dan misi mereka, maka dari itu diperlukan suatu pengendalian risiko agar mampu membantu suatu organisasi atau perusahaan untuk menangani setiap risiko yang ada dan mampu mewujudkan tujuan dari organisasi atau perusahaan tersebut.

Penelitian sebelumnya yang membahas pula tentang ISO 31000 dilakukan oleh Penelitian tentang Analisis Risiko Teknologi Informasi Menggunakan ISO 31000 (Studi kasus: Sistem Penjualan PT Matahari Department Store Cabang Malang Town Square). Pada penelitian ini mencoba mengimplementasikan suatu analisis manajemen risiko menggunakan ISO 31000 yang dapat digunakan untuk mengelola risiko secara keseluruhan pada suatu area kegiatan sehingga perusahaan dapat melakukan pencegahan, penanganan, serta perbaikan ke depannya. Analisis risiko menggunakan ISO 31000 terlihat nilai risiko dengan tiga tingkatan yaitu rendah, sedang, dan tinggi. Berdasarkan hasil analisis, rekomendasi pengendalian yang tepat seperti risk reduction untuk risiko human error (kesalahan dalam mengoperasikan sistem), risk avoidance untuk risiko pencurian password otorisasi, serta risk reduction untuk risiko koneksi yang tidak stabil (Driantami, dkk, 2018)

Penelitian yang berkaitan dengan ISO 31000 dilakukan oleh Stefan Agustinus dengan judul "Analisis Risiko Teknologi Informasi Menggunakan ISO 31000 pada Program HRMS" pada tahun 2017. Penelitian tersebut membahas tentang penilaian risiko terhadap aset-aset yang ada di sekitar perusahaan. Dalam penelitian ini ditemukan 2 kemungkinan risiko memiliki level of risk dengan tingkatan high dan 18 kemungkinan risiko dengan tingkatan medium yang dapat mengganggu kinerja perusahaan. Dengan adanya penilaian risiko, diharapkan mampu meminimalkan kerugian yang dialami perusahaan (Agustinus, dkk., 2017)

\section{RUANG LINGKUP}

Ruang lingkup dari penelitian ini adalah aset teknologi informasi website dan mengidentifikasi risiko yang ada di Toko Ujung Pandang Grosir Penajam Paser Utara dengan menggunakan Framework ISO 31000:2018.

Pada penelitian ini peneliti melakukan analisis kemungkinan risiko, mengelompokkan kemungkinan risiko berdasarkan dampak nya sehingga menghasilkan usulan tindakan risiko terhadap kemungkinan risiko yang terdapat pada website di Toko Ujung Pandang Grosir Penajam Paser Utara.

\section{BAHAN DAN METODE}

Bahan kajian, metode dan tahapan penelitian yang akan dilakukan dalam penelitian ini adalah sebagai berikut:

\subsection{Risiko}

Risiko merupakan kombinasi dari kemungkinan dan parah nya dari suatu kejadian. Besarnya risiko ditentukan oleh berbagai faktor, seperti besarnya paparan, lokasi, pengguna, kuantitas serta kerentanan unsur yang terlibat (Sirait \& Susanty, 2016). manajemen risiko merupakan suatu rangkaian prosedur dan metodologi yang digunakan untuk mengidentifikasi, mengukur, memonitor dan mengontrol risiko yang timbul dari bisnis operasional perusahaan (Suhendra, dkk, 2013). Sasaran dari pelaksanaan manajemen risiko adalah mengurangi risiko yang berbeda-beda yang berkaitan dengan bidang yang telah dipilih pada tingkat yang dapat diterima oleh masyarakat. Hal ini dapat berupa berbagai jenis ancaman yang disebabkan oleh lingkungan, teknologi, manusia, organisasi dan politik. Di sisi lain pelaksanaan manajemen risiko melibatkan segala cara yang tersedia bagi manusia, khususnya, bagi entitas manajemen risiko (manusia, staf, dan organisasi) Risiko selalu berhubungan dengan ketidakpastian sehingga dalam kegiatan apapun pasti tidak akan terhindar dari sebuah 
risiko. Risiko selalu mengikuti semua kegiatan baik di bidang pengelolaan keuangan, pengelolaan perusahaan maupun dalam kehidupan sehari-hari. Maka diperlukan suatu cara untuk mengatasi risiko tersebut yang disebut manajemen risiko. Manajemen risiko adalah suatu cara untuk mengelola risiko tersebut agar menjadi sebuah peluang, bahkan bisa menjadi ancaman juga bagi perusahaan lain (Bambang \& Lestari, 2018)

\subsection{Manajemen Risiko}

Manajemen risiko merupakan upaya manajemen untuk mengendalikan risiko pada kegiatan operasional perusahaan, dengan melakukan analisis risiko, evaluasi risiko, serta rencana penanggulangannya (Berg, 2016). Dengan adanya manajemen risiko yang dikelola dengan baik, perusahaan dapat melindungi nilai (protecting value) dan menambah nilai (creating value) perusahaan (Yap, 2017). Peran dari manajemen Risiko diharapkan dapat mengantisipasi lingkungan cepat berubah, mengembangkan corporate governance, mengoptimalkan strategic management, mengamankan sumber daya dan asset yang dimiliki organisasi, dan mengurangi reactive decision making dari manajemen puncak. Risiko dapat dikendalikan melalui manajemen Risiko. Peran dari manajemen Risiko diharapkan dapat mengantisipasi lingkungan cepat berubah, mengembangkan corporate governance, mengoptimalkan strategic management, mengamankan sumber daya dan asset yang dimiliki organisasi, dan mengurangi reactive decision making dari manajemen puncak (Budi, 2014).

\subsection{Identifikasi Risiko}

Identifikasi Risiko merupakan suatu proses dalam menentukan apa, bagaimana, dan mengapa suatu kejadian dapat terjadi. Proses identifikasi risiko harus dilakukan secara komprehensif/menyeluruh agar nantinya risiko dapat dinilai secara sistematis (Mochammad Husein \& Imbar, 2015)

\subsection{ISO 31000:2018}

ISO 31000 merupakan standar yang berkaitan dengan manajemen risiko yang di kodifikasi oleh International Organization for Standardization (ISO) (Francisca Lady Nice, 2016). Pada penerapannya, ISO 31000 dapat diterapkan dalam berbagai jenis usaha publik atau swasta serta mampu menyiapkan prinsip dan tahapan mengelola risiko sehingga bisa digunakan sebagai gambaran dalam manajemen risiko guna menerapkan manajemen risiko yang lebih efektif (Bahrudin, 2016).Tujuan dari ISO sendiri adalah untuk memberikan prinsip-prinsip dan pedoman untuk manajemen risiko yang diakui secara universal. ISO 31000 adalah panduan penerapan risiko yang terdiri atas tiga elemen: prinsip (principle), kerangka kerja (framework), dan proses (process). Prinsip manajemen risiko adalah dasar praktik atau filosofi manajemen risiko. Secara umum, ISO 31000:2018 menyederhanakan versi 2009. Hal itu langsung terlihat antara lain dari nama yang berubah dari "principles and guidelines" menjadi hanya "guidelines" serta dari jumlah halaman yang menyusut dari 24 halaman menjadi 16 halaman. Diagram yang menggambarkan hubungan prinsip, kerangka kerja, dan proses manajemen proses pun berubah. Pada versi 2009, prinsip, kerangka kerja, dan proses digambarkan sebagai rangkaian unsur yang berurutan, sedangkan pada versi 2018 ketiga bagian ini digambarkan sebagai sistem terbuka yang saling berkaitan (Lanin, 2018)

Menurut ISO 31000, manajemen risiko suatu organisasi harus mengikuti 11 prinsip dasar agar dapat dilaksanakan secara efektif. Berikut penjabaran prinsip-prinsip tersebut. Yaitu : Manajemen risiko menciptakan nilai tambah, Manajemen risiko adalah bagian integral proses dalam organisasi, Manajemen risiko adalah bagian dari pengambilan keputusan, Manajemen risiko secara eksplisit menangani ketidakpastian Manajemen risiko bersifat sistematis, terstruktur, dan tepat waktu, Manajemen risiko berdasarkan informasi terbaik yang tersedia, Manajemen risiko dibuat sesuai kebutuhan, Manajemen risiko memperhitungkan faktor manusia dan budaya, Manajemen risiko bersifat transparan dan inklusif, Manajemen risiko bersifat dinamis, iteratif, dan responsif terhadap perubahan, Manajemen risiko memfasilitasi perbaikan dan pengembangan berkelanjutan organisasi (Qintharah, 2019)

Prinsip manajemen risiko berubah dari 11 prinsip pada versi 2009 menjadi 1 tujuan (purpose) dan 8 prinsip pada versi 2018. Satu prinsip, yaitu "penciptaan dan pelindungan nilai", diubah menjadi tujuan manajemen risiko. Dua prinsip, yaitu "bagian pengambilan keputusan" dan "secara eksplisit menangani ketidakpastian", dihapus. Delapan prinsip lain disederhanakan pernyataannya menjadi, terintegrasi, terstruktur dan komprehensif, disesuaikan, inklusif, dinamis, informasi terbaik yang tersedia, faktor manusia dan budaya, serta peningkatan sinambung. Gambar lebih detail proses manajemen risiko ISO 31000:2018 dapat dilihat pada gambar 1 


\begin{tabular}{l} 
a) Creates value \\
b) Integral part of \\
organizational processes \\
c) Part of decision making \\
d) Explicitly addresses \\
uncertainty \\
e) Systematic, structured \\
and timely \\
f) Based on the best \\
available information \\
g) Tailored \\
h) Takes human and \\
cultural factors into \\
account \\
i) Transparent and inclusive \\
j) Dynamic, iterative and \\
responsive to change \\
k) Facilitates continual \\
improvement and \\
enhancement of the \\
oraanization \\
\hline \multicolumn{1}{c}{ Principles } \\
(Clause 3 )
\end{tabular}

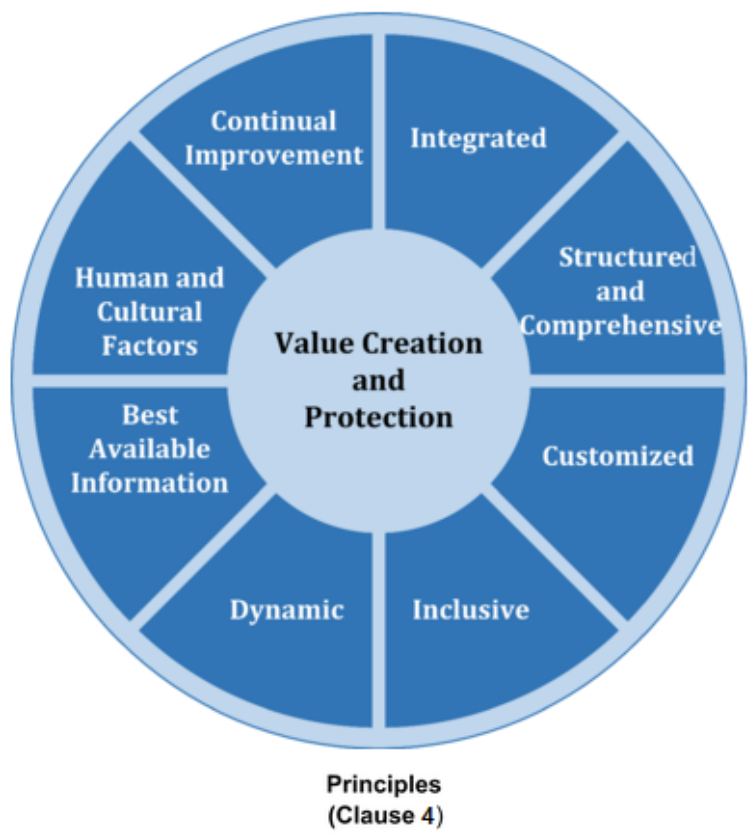

Gambar 1. Perbedaan ISO 31000:2009 dan ISO 31000:2018

\subsection{Metode Penelitian}

Peneliti menggunakan metode penelitian Case Study Research dengan pendekatan kualitatif. Pendekatan ini dilakukan dengan mendeskripsikan atau menguraikan data dan fakta yang terjadi di dalam objek studi kasus kedalam bentuk kata-kata. Salah satu jenis pendekatan kualitatif ini adalah metode penelitian Case Study Research, dimana metode ini hanya berfokus pada satu objek tertentu, dengan metode ini peneliti akan dengan mudah mendapatkan data-data yang dibutuhkan untuk menyelesaikan permasalahan yang terjadi pada objek studi kasus. Dalam metode Case Study Research ini dilakukan dengan beberapa tahapan dimana tahapantahapan ini sesuai dengan manajemen risiko dari framework ISO 31000: 2018. Dimana untuk melakukan riset ini dalam mencari segala informasi yang dibutuhkan guna menunjang penelitian terhadap website di Toko Ujung Pandang Grosir Penajam. Data yang didapatkan ini berupa data primer yang didapatkan melalui wawancara dengan pihak internal terkait penelitian ini dan melakukan observasi ke lokasi toko grosir ujung pandang yang terletak di Penajam paser utara (Hutabarat \& Manuputty, 2020)

Pada gambar 2 menjelaskan metode yang digunakan peneliti dalam menganalisis data, tahapantahapan yang dimulai dari Risk Assessment sampai Risk Treatment, dengan cara-cara yang digunakan agar penelitian berjalan dengan baik antara lain memperhitungkan scope, context, dan criteria dari risiko, lalu melakukan konsultasi dan komunikasi dengan pihak terkait, kemudian melihat track record sera reporting. Dan terakhir melakukan monitoring dan review.

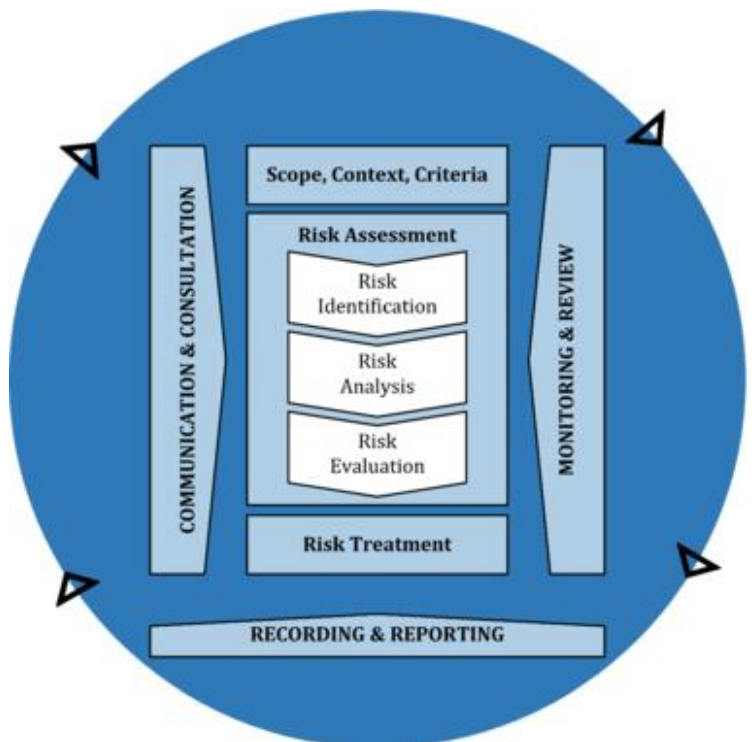

Gambar 2. Metode Analisis Data 
Seperti pada gambar 2 tahapan pertama adalah

1. Risk Assessment (Penilaian Risiko). Penilaian risiko merupakan metode yang sistematis dalam menentukan apakah dalam website di Toko Ujung Pandang Grosir Penajam memiliki risiko yang dapat diterima atau tidak. Dalam Penilaian Risiko ini terdiri dari beberapa tahapan

2. Risk Identification (Identifikasi risiko). Merupakan usaha untuk mencari dan mengetahui risiko-risiko yang memiliki kemungkinan muncul dalam kegiatan- kegiatan yang dilakukan oleh perusahaan.

3. Risk Analyst (Analisis Risiko)

Dalam metode analisis risiko ini meliputi faktor penilaian, karakterisasi, manajemen dan kebijakan yang berkaitan dengan risiko dalam perusahaan.

4. Risk Evaluation (Evaluasi Risiko)

Evaluasi risiko ini merupakan proses untuk membandingkan antara level risiko mulai dari risiko terendah hingga risiko yang paling tinggi yang ditemukan selama proses analisis. Dalam evaluasi ini bertujuan untuk membantu proses pengambilan risiko berdasarkan hasil analisis risiko.

5. RiskTreatment (Perlakuan Risiko)

Risk treatment bertujuan untuk menentukan tindakan yang dilakukan dalam mengatasi risiko yang telah teridentifikasi, guna mengurangi pengaruh risiko secara keseluruhan (Dale F. Cooper, Stephen Grey \& Walker, 2005) dalam tahapan ini melibatkan pemilihan satu atau lebih pilihan untuk menanggulangi risiko dan menerapkan penanganan risiko. Setelah diimplementasikan, penanganan risiko dapat dilakukan maupun dimodifikasi dalam kontrol penanganan risiko Dalam proses ini melibatkan.

1) Menilai penanganan risiko

2) Memutuskan apakah tingkat risiko dapat di toleransi atau tidak

3) Jika tidak dapat di toleransi berarti akan menghasilkan penanganan risiko baru

4) Menilai efektivitas dari penanganan tersebut

\section{PEMBAHASAN}

Pembahasan dalam penelitian ini adalah melakukan analisis kemungkinan risiko, mengelompokkan kemungkinan risiko berdasarkan dampak nya sehingga menghasilkan usulan tindakan risiko terhadap kemungkinan risiko yang terdapat pada website di Toko Ujung Pandang Grosir Penajam Paser Utara. Penelitian ini menggunakan metode penelitian Case Study Research, dimana metode ini hanya berfokus pada satu objek tertentu, dengan metode ini peneliti akan dengan mudah mendapatkan data-data yang dibutuhkan untuk menyelesaikan permasalahan yang terjadi pada objek studi kasus. Dalam metode Case Study Research ini dilakukan dengan beberapa tahapan dimana tahapantahapan ini sesuai dengan manajemen risiko dari framework ISO 31000: 2018. Dimana untuk melakukan riset ini dalam mencari segala informasi yang dibutuhkan guna menunjang penelitian terhadap website di Toko Ujung Pandang Grosir Penajam. Data yang didapatkan ini berupa data primer yang didapatkan melalui wawancara dengan pihak internal terkait penelitian ini dan melakukan observasi ke lokasi toko grosir ujung pandang yang terletak di Penajam paser utara.

\subsection{Penilaian Risiko}

Pada tahap ini merupakan tahap penilaian risiko di Toko Ujung Pandang Grosir Penajam. Pada Proses penilaian risiko aplikasi website toko ujung pandang di penajam paser utara ini terdiri dari 3 tahap yaitu: Identifikasi risiko (risk identification), analisis risiko (risk analysis), evaluasi risiko (risk evaluation).

\subsection{Identifikasi Risiko}

Pada tahap pertama, dilakukan identifikasi aset yang berhubungan dengan website seperti aset data, aset perangkat lunak (Software), dan aset perangkat keras (Hardware). Dan dalam identifikasi ini mewawancarai Pemilik Toko Ujung Pandang Grosir Penajam dan Staff IT atau bagian yang mengurusi sistem website. Pada tahap ini memfokuskan pada aset data, software dan hardware-nya pada tabel 1 .

Tabel 1. Identifikasi Aset

\begin{tabular}{|c|c|}
\hline $\begin{array}{c}\text { Komponen Sistem } \\
\text { Informasi }\end{array}$ & Aset \\
\hline Data & $\begin{array}{c}\text { Data barang, data supplier, } \\
\text { data karyawan }\end{array}$ \\
\hline Software & $\begin{array}{c}\text { Website toko ujung } \\
\text { pandang }\end{array}$ \\
\hline Hardware & $\begin{array}{c}\text { Personal computer, } \\
\text { database server }\end{array}$ \\
\hline
\end{tabular}

Pada tabel 1 memperlihatkan aset dari komponen sistem informasi yang berupa data, software, dan hardware yang mendukung perkembangan website toko ujung pandang

\subsection{Identifikasi Kemungkinan Masalah Risiko}

Dalam tahap identifikasi kemungkinan masalah risiko yang bertujuan untuk mengidentifikasi kemungkinan risiko yang muncul dan terjadi pada aset melalui proses wawancara di toko ujung pandang di penajam paser utara. identifikasi ini kemungkinan masalah risiko yang terlihat pada tabel 2 . 
Tabel 2. Identifikasi Kemungkinan Risiko

\begin{tabular}{|l|l|}
\hline No & \multicolumn{1}{|c|}{ Kemungkinan Risiko } \\
\hline R1 & Penyalahgunaan hak akses website \\
\hline R2 & Kesalahan yang dilakukan karyawan (human error) \\
\hline R3 & Pencurian Hardware \\
\hline R4 & Koneksi jaringan yang buruk (gangguan) \\
\hline R5 & Vandalism (merusak fasilitas seperti perangkat komputer) \\
\hline R6 & User interface sulit dipahami \\
\hline R7 & Kerusakan Hardware \\
\hline R8 & Server down \\
\hline R9 & Data Korup \\
\hline R10 & Overheat \\
\hline R11 & Trouble Backup \\
\hline R12 & Sistem Error \\
\hline R13 & Listrik Padam \\
\hline R14 & Kebakaran \\
\hline R15 & Petir \\
\hline R16 & CCTV tidak berfungsi dengan baik (rusak) \\
\hline
\end{tabular}

Berdasarkan dari tahapan identifikasi risiko yang dilakukan dengan wawancara kepada pihak toko ujung pandang di penajam paser utara ditemukan ada 16 kemungkinan - kemungkinan risiko. Setelah mengetahui identifikasi dari kemungkinan risiko, pada tahap berikutnya melakukan identifikasi dampak risiko dari kemungkinan - kemungkinan risiko yang ada pada tabel 3 .

Tabel 3. Kemungkinan Risiko dan Dampak

\begin{tabular}{|c|c|c|}
\hline No & Kemungkinan Risiko & Dampak \\
\hline $\mathrm{R} 1$. & Penyalahgunaan hak akses website & $\begin{array}{l}\text { Hakakses } \text { user } \\
\text { Dapat disalahgunakan }\end{array}$ \\
\hline $\mathrm{R} 2$. & $\begin{array}{l}\text { Kesalahan yang dilakukan karyawan (human } \\
\text { error) }\end{array}$ & $\begin{array}{l}\text { - Menyebabkan kecelakaan kerja } \\
\text { - Proses kerja terhambat }\end{array}$ \\
\hline R3. & Pencurian Hardware & $\begin{array}{l}\text { User dapat mengalami kesulitan dalam memahami dan menjalankan } \\
\text { sistem }\end{array}$ \\
\hline R4. & Koneksi jaringan yang buruk (gangguan) & User akan kesulitan dalam mengakses sistem \\
\hline R5. & $\begin{array}{l}\text { Vandalism (merusak fasilitas seperti perangkat } \\
\text { komputer) }\end{array}$ & Kerugian finansial dan menyebabkan perangkat menjadi rusak \\
\hline R6. & User interface sulit dipahami & $\begin{array}{l}\text { User dapat mengalami kesulitan dalam memahami dan menjalankan } \\
\text { sistem }\end{array}$ \\
\hline R7. & Kerusakan Hardware & $\begin{array}{l}\text { Menghambat proses bisnis dan user akan kesulitan dalam mengakses } \\
\text { sistem }\end{array}$ \\
\hline R8. & Server down & $\begin{array}{l}\text { - Menghambat proses bisnis yang sedang berjalan dalam bidang } \\
\text { pemasaran } \\
\text { - Aplikasi yang ada di dalam perusahaan menjadi error / tidak dapat } \\
\text { berjalan dengan baik }\end{array}$ \\
\hline R9. & Data Korup & User tidak dapat melihat data yang valid \\
\hline R10. & Overheat & software aplikasi yang sedang digunakan menjadi lambat / error \\
\hline R11. & Trouble Backup & Dapat menyebabkan kehilangan data \\
\hline R12. & Sistem Error & User akan mengalami kesulitan dalam menjalankan sistem \\
\hline R13. & Listrik Padam & $\begin{array}{l}\text { - Kerugian operasional perusahaan } \\
\text { - Mengganggu proses kerja server } \\
\text { - Kualitas server menurun }\end{array}$ \\
\hline R14. & Kebakaran & $\begin{array}{l}\text { - Kerusakan sarana dan prasarana perusahaan } \\
\text { - Kerugian materiil } \\
\text { - Menghambat aktivitas perusahaan } \\
\end{array}$ \\
\hline R15. & Petir & Kerusakan sarana dan prasarana perusahaan \\
\hline R16. & CCTV tidak berfungsi dengan baik (rusak) & $\begin{array}{l}\text { - Pemantauan proses kerja di perusahaan menjadi kurang efektif } \\
\text { - Berkurangnya tingkat keamanan }\end{array}$ \\
\hline
\end{tabular}

Dari tabel 3 tentang identifikasi dampak kemungkinan risiko diatas maka dapat dilihat dampak yang ditimbulkan dari kemungkinan risiko yang terjadi.

\subsection{Analisis Risiko}

Analisis manajemen risiko adalah suatu kegiatan yang dilakukan pada tingkat pimpinan pelaksana, yaitu berupa kegiatan penemuan dan analisis sistematis atas 
kerugian yang mungkin saja dapat dihadapi oleh sebuah perusahaan, akibat suatu risiko serta cara pengendalian yang paling tepat untuk menangani kerugian yang dihubungkan dengan tingkat keuntungan perusahaan. Pada tahap ini dilakukan penilaian terhadap kemungkinan risiko pada tahap identifikasi risiko sebelumnya, dengan menggunakan tabel kriteria Likelihood. Pada tabel 4 Likelihood terdapat 5 kriteria yang berdasarkan frekuensi kejadian kemungkinan risiko terjadi.

Tabel 4. Kriteria Likelihood

\begin{tabular}{|c|c|c|c|}
\hline \multicolumn{2}{|c|}{ Likelihood } & \multirow{2}{*}{ Deskripsi } & \multirow{2}{*}{$\begin{array}{l}\text { Frekuensi } \\
\text { Kejadian }\end{array}$} \\
\hline Nilai & Kriteria & & \\
\hline 1 & Rare & $\begin{array}{l}\text { Risiko tersebut } \\
\text { hampir tidak } \\
\text { pernah terjadi }\end{array}$ & $>2$ Tahun \\
\hline 2 & Unlikely & $\begin{array}{l}\text { Risiko tersebut } \\
\text { jarang terjadi }\end{array}$ & $1-2$ Tahun \\
\hline 3 & Possible & $\begin{array}{l}\text { Risiko tersebut } \\
\text { kadang terjadi }\end{array}$ & $7-12$ Bulan \\
\hline 4 & Likely & $\begin{array}{l}\text { Risiko tersebut } \\
\text { sering terjadi }\end{array}$ & $4-6$ Bulan \\
\hline 5 & Certain & $\begin{array}{l}\text { Risiko tersebut } \\
\text { pasti terjadi }\end{array}$ & $1-3$ Bulan \\
\hline
\end{tabular}

Dampak yang terjadi dari kemungkinan risiko di Toko Ujung Pandang Grosir Penajam Paser Utara. Pada tabel penilaian dampak ini dikelompokkan kedalam 5 kriteria dan dikelompokkan berdasarkan mulai dari dampak yang paling tidak berpengaruh sampai dampak yang paling berpengaruh.

Pada tabel 5 merupakan kriteria Impact yang terdiri dari impact dengan nilai dan kriteria serta terdapat keterangan.

Tabel 5. Kriteria Impact

\begin{tabular}{|c|c|l|}
\hline \multicolumn{2}{|c|}{ Impact } & \multicolumn{1}{|c|}{ Keterangan } \\
\hline Nilai & Kriteria & $\begin{array}{l}\text { Tidak Mengganggu } \\
\text { aktivitas }\end{array}$ \\
\hline 1 & Insignificant & $\begin{array}{l}\text { aktivitas Perusahaan } \\
\text { Sedikit Terhambat }\end{array}$ \\
\hline 3 & Minor & $\begin{array}{l}\text { Menyebabkan Gangguan } \\
\text { Pada Proses Bisnis }\end{array}$ \\
\hline 4 & Majorate & $\begin{array}{l}\text { Menghambat hampir } \\
\text { seluruh aktivitas }\end{array}$ \\
\hline 5 & Catastrophic & $\begin{array}{l}\text { aktivitas perusahaan } \\
\text { berhenti }\end{array}$ \\
\hline
\end{tabular}

Setelah mendapatkan kriteria kemungkinan (Likelihood) di tabel 4, dan kriteria dampak (Impact) di tabel 5. Maka selanjutnya penilaian terhadap kemungkinan risiko berdasarkan tabel 4 dan 5 . Selanjutnya penilaian likelihood dan impact pada tabel 6 .
Tabel 6. Penilaian Likelihood dan Impact

\begin{tabular}{|c|c|c|c|}
\hline No & Kemungkinan Risiko & Likelihood & Impact \\
\hline R1 & $\begin{array}{l}\text { Penyalahgunaan } \\
\text { akses website }\end{array}$ & 2 & 1 \\
\hline $\mathrm{R} 2$ & $\begin{array}{l}\text { Kesalahan } \quad \text { yang } \\
\text { dilakukan } \\
\text { (human error) }\end{array}$ & 4 & 1 \\
\hline R3. & Pencurian Hardware & 1 & 3 \\
\hline R4. & $\begin{array}{l}\text { Koneksi jaringan yang } \\
\text { buruk (gangguan) }\end{array}$ & 4 & 2 \\
\hline R5. & $\begin{array}{lr}\text { Vandalism } & \text { (merusak } \\
\text { fasilitas } & \text { seperti } \\
\text { perangkat komputer) }\end{array}$ & 1 & 3 \\
\hline R6. & $\begin{array}{l}\text { User interface sulit } \\
\text { dipahami }\end{array}$ & 2 & 1 \\
\hline R7. & Kerusakan Hardware & 2 & 4 \\
\hline R8. & Server down & 4 & 4 \\
\hline R9. & Data Korup & 1 & 4 \\
\hline R10. & Overheat & 4 & 1 \\
\hline R11. & Trouble Backup & 1 & 2 \\
\hline R12. & Sistem Error & 3 & 4 \\
\hline R13. & Listrik Padam & 3 & 3 \\
\hline R14. & Kebakaran & 1 & 5 \\
\hline R15. & Petir & 2 & 3 \\
\hline R16. & $\begin{array}{l}\text { CCTV tidak berfungsi } \\
\text { dengan baik (rusak) }\end{array}$ & 3 & 1 \\
\hline
\end{tabular}

\section{Evaluasi Risiko}

Pada tahapan terakhir yaitu evaluasi risiko akan dilakukan proses evaluasi risiko dari kemungkinan kemungkinan risiko yang sudah di analisis pada tahapan sebelumnya.

Dari hasil analisis tersebut akan dimasukkan ke dalam matrix evaluasi risiko berdasarkan pedoman yang ada di dalam kerangka kerja ISO 31000. Matrix evaluasi pada tabel 7 dibedakan menjadi 3 level risiko yaitu: Low, Medium, dan High.

Pada tabel 7 menjelaskan tentang rasio pengelompokan berdasarkan level risiko dari yang tertinggi (high), hingga terendah (low). Tahap selanjutnya yaitu memasukkan setiap identitas kemungkinan risiko kedalam matrix evaluasi risiko sesuai dengan kriteria Likelihood dan kriteria Impact. 
Tabel 7. Matrix Evaluasi Risiko

\begin{tabular}{|l|l|l|l|l|}
\hline No & $\begin{array}{l}\text { Kemungkinan } \\
\text { Risiko }\end{array}$ & $\begin{array}{l}\text { Likelihoo } \\
\text { d }\end{array}$ & Impact & $\begin{array}{l}\text { Risk } \\
\text { Level }\end{array}$ \\
\hline R8 & Server down & 4 & 4 & High \\
\hline R2 & $\begin{array}{l}\text { Kesalahan yang } \\
\text { dilakukan } \\
\text { karyawan } \\
\text { (human error) }\end{array}$ & 4 & 1 & Medium \\
\hline R4 & $\begin{array}{l}\text { Koneksi } \\
\text { jaringan yang } \\
\text { buruk } \\
\text { (gangguan) }\end{array}$ & 4 & 2 & Medium \\
\hline R7 & $\begin{array}{l}\text { Kerusakan } \\
\text { hardware }\end{array}$ & 2 & 4 & Medium \\
\hline R10 & Overheat & 4 & 1 & Medium \\
\hline
\end{tabular}

Selanjutnya tabel 8 Berdasarkan Likelihood dan Impact beberapa kemungkinan risiko dapat dikategorikan dengan rasio yang sesuai.

Tabel 8. Matrix Evaluasi Risiko Berdasarkan Likelihood dan Impact

\begin{tabular}{|c|c|c|c|c|c|c|c|}
\hline \multirow{7}{*}{ 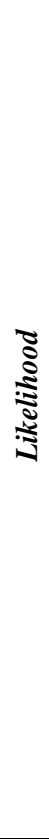 } & Certain & 5 & & & & & \\
\hline & Likely & 4 & $\begin{array}{c}\mathrm{R} 2 \\
\mathrm{R} 10\end{array}$ & R4 & & R8 & \\
\hline & Possible & 3 & R16 & & R13 & R12 & \\
\hline & Unlikely & 2 & $\begin{array}{l}\text { R1 } \\
\text { R6 }\end{array}$ & & & $\begin{array}{l}\text { R7 } \\
\text { R9 }\end{array}$ & \\
\hline & Rare & 1 & R15 & R11 & $\begin{array}{l}\text { R3 } \\
\text { R5 }\end{array}$ & & \\
\hline & & & 1 & 2 & 3 & 4 & 5 \\
\hline & Impact & & 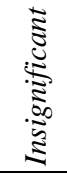 & 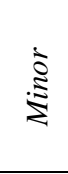 & 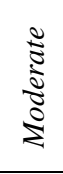 & $\frac{\dot{s}}{3}$ & 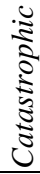 \\
\hline
\end{tabular}

Berdasarkan Likelihood dan Impact beberapa kemungkinan risiko dapat dikategorikan dengan rasio yang sesuai seperti pada tabel 8. Setelah memasukan kemungkinan risiko ke dalam matrix evaluasi berdasarkan likelihood dan impact. Pada tahapan berikutnya akan di dikelompokkan 16 kemungkinan risiko diatas kedalam tingkatan level high, medium dan low. Setelah tabel 8 selanjutnya pada tabel 9 tahapan proses evaluasi risiko diatas, terdapat 20 kemungkinan risiko yang sudah di analisis serta di kelompokkan berdasarkan level risikonya.
Tabel 9. Pengelompokan Risiko Berdasarkan Tingkatan

\begin{tabular}{|c|l|c|c|c|}
\hline R12 & Sistem error & 3 & 4 & Medium \\
\hline R13 & Listrik padam & 3 & 3 & Medium \\
\hline R1 & $\begin{array}{l}\text { Penyalahguna } \\
\text { an hak akses } \\
\text { website }\end{array}$ & 2 & 1 & Low \\
\hline R3 & $\begin{array}{l}\text { Pencurian } \\
\text { Hardware }\end{array}$ & 1 & 3 & Low \\
\hline R5 & $\begin{array}{l}\text { Vandalism } \\
\text { (merusak } \\
\text { fasilitas } \\
\text { seperti } \\
\text { perangkat } \\
\text { lunak) }\end{array}$ & 1 & 3 & Low \\
\hline R6 & $\begin{array}{l}\text { User interface } \\
\text { sulit dipahami }\end{array}$ & 2 & 1 & Low \\
\hline R11 & $\begin{array}{l}\text { Trouble } \\
\text { Backup }\end{array}$ & 1 & 2 & Low \\
\hline R15 & Petir & 2 & 3 & Low \\
\hline R16 & $\begin{array}{l}\text { CCTV tidak } \\
\text { berfungsi } \\
\text { (rusak) }\end{array}$ & 3 & 1 & Low \\
\hline
\end{tabular}

\section{KESIMPULAN}

Penelitian analisis risiko teknologi informasi menggunakan ISO 31000:2018 pada website yang dimiliki Toko Ujung Pandang Grosir Penajam Paser Utara mulai dari tahapan penilaian risiko, identifikasi risiko, analisis risiko, evaluasi risiko, hingga tahap perlakukan risiko. Dari tahapan-tahapan tersebut, analisis risiko ini mendapatkan 16 kemungkinan risiko yang dapat sewaktu-waktu bisa mengganggu kinerja Website maupun mengganggu proses bisnis yang terdapat di Toko Ujung Pandang Grosir Penajam. Terdapat 1 kemungkinan risiko dengan tingkat High meliputi server down. Kemudian terdapat 6 kemungkinan risiko dengan tingkat Medium meliputi Kesalahan yang dilakukan karyawan (human error), koneksi jaringan yang buruk(gangguan), Kerusakan Hardware, Overheat, Sistem error, dan listrik padam. Kemudian juga terdapat 7 kemungkinan risiko dengan tingkat Low yang meliputi penyalahgunaan hak akses website, pencurian hardware, vandalism (merusak fasilitas seperti perangkat lunak), User interface sulit dipahami, Trouble backup, petir, dan CCTV tidak berfungsi dengan baik (rusak)

\section{SARAN}

Penelitian ini ke depannya lebih memperhatikan asset yang berada dalam lingkungan website di Toko Ujung Pandang Grosir Penajam Paser Utara tersebut, selain itu diharapkan penelitian ini dapat digunakan perusahaan Toko Ujung Pandang Grosir Penajam Paser Utara sebagai pedoman atau kebijakan untuk meminimalisasi kemungkinan - kemungkinan risiko yang dapat terjadi dengan menggunakan usulan tindakan risiko seperti melakukan pengecekan berskala pada database, menggunakan ISP terbaru, membuat SOP, memasang 
CCTV. Terutama pada kemungkinan risiko dengan tingkat High, supaya tidak mengganggu sistem website di Toko Ujung Pandang Penajam Paser Utara.

\section{DAFTAR PUSTAKA}

Adi, D. E., \& Susanto, N. (2017). Analisis Manajemen Risiko Aktivitas Pengadaan pada Percetakan Surat Kabar. Jurnal Metris, 18, 113-118.

Agustinus, S., Nugroho, A., \& Cahyono, A. D. (2017). Analisis Risiko Teknologi Informasi Menggunakan ISO 31000 pada Program HRMS. Jurnal RESTI (Rekayasa Sistem Dan Teknologi Informasi), 1(3), 250-258. https://doi.org/10.29207/resti.v1i3.94

Angraini, \& Pertiwi, I. D. (2017). Analisa Pengelolaan Risiko Penerapan Teknologi Informasi Menggunakan Iso 31000. Jurnal Ilmiah Rekayasa Dan Manajemen Sistem Informasi, Vol. 3,(2), 7076.

Bahrudin, M. (2016). Desain Implementasi ISO 31000 Sebagai Panduan Manajemen Risiko Di Unit Dokumentasi Dan Data Standarisasi Pusido BSN. Conference: Seminar Dan Knowledge Sharing Kepustakawanan Forum Perpusdokinfo LPNK Ristek, June 2016.

Bambang, W., \& Lestari, dan N. P. (2018). Manajemn Resiko dan Asuransi. UMM Press.

Berg, H.-P. (2016). RISK MANAGEMENT: PROCEDURES, METHODS AND EXPERIENCES. Liquid Crystals XX, 9940(17), 994008. https://doi.org/10.1117/12.2235677

Budi, A. S. (2014). Analisis Risk Management berbasis ISO 31000 untuk mengurangi wanprestasi kontrak pada CV. Putra Pertama di Surabaya. Jurnal Ilmiah Mahasiswa Universitas Surabaya, 3(1), 1-8.

Dale F. Cooper, Stephen Grey, G. R., \& Walker, and P. (2005).

Project.Risk.Management.Guidelines.Managing.Ri sk in Large Projects and Complex Procurements.

Driantami, H. T. I., Suprapto, \& Perdanakusuma, A. R. (2018). Analisis Risiko Teknologi Informasi Menggunakan ISO 31000 ( Studi kasus: Sistem Penjualan PT Matahari Department Store Cabang Malang Town Square ). Jurnal Pengembangan Teknologi Informasi Dan Ilmu Komputer, 2(11), 4991-4998.

Francisca Lady Nice, R. V. I. (2016). Analisis Risiko Teknologi Informasi pada Lembaga Penerbangan dan Antariksa Nasional (LAPAN) pada Website SWIFTS Menggunakan ISO 31000. Juisi, 2(2), 1689-1699.

Hutabarat, F. M., \& Manuputty, A. D. (2020). Analisis Resiko Teknologi Informasi Aplikasi VCare PT Visionet Data Internasional Menggunakan ISO 31000. Jurnal Bina Komputer, 2(1), 52-65. https://doi.org/10.33557/binakomputer.v2i1.792

Lanin, I. (2018). Standar Baru Manajemen Risiko ISO 31000:2018. Www.Linkedin.Com/Pulse/StandarBaru-Manajemen-Risiko-Iso-310002018-Ivan-
Lanin. https://grc-indonesia.com/standar-barumanajemen-risiko-iso-310002018/

Mochammad Husein, G., \& Imbar, R. V. (2015) Analisis Manajemen Risiko Teknologi Informasi Penerapan Pada Document Management System di PT. JABAR TELEMATIKA (JATEL). Jurnal Teknik Informatika Dan Sistem Informasi, 1(2), 75-87. https://doi.org/10.28932/jutisi.v1i2.368

Naibaho, R. S. (2017). Peranan Dan Perencanaan Teknologi Informasi Dalam Perusahaan. Jurnal Warta, April, 4 https://media.neliti.com/media/publications/29073 1-peranan-dan-perencanaan-teknologi-informad00d595.pdf

Pramanda, R. P., Azizah, D. F., \& Astuti, E. S. (2016). Pengaruh Kemudahan Dan Kemanfaatan Penggunaa Teknologi Informasi Terhadap Kinerja Karyawan. Jurnal Administrasi Bisnis, 39(2), 117 126.

Qintharah, Y. N. (2019). Perancangan Penerapan Manajemen Risiko. JRAK: Jurnal Riset Akuntansi Dan Komputerisasi Akuntansi, 10(1), 67-86. https://doi.org/10.33558/jrak.v10i1.1645

Ramadhan, D. L., Febriansyah, R., \& Dewi, R. S. (2020). Analisis Manajemen Risiko Menggunakan ISO 31000 pada Smart Canteen SMA XYZ. JURIKOM (Jurnal Riset Komputer), 7(1), 91. https://doi.org/10.30865/jurikom.v7i1.1791

Sirait, N. M., \& Susanty, A. (2016). Analisis Risiko Operasional Berdasarkan Pendekatan Enterprise Risk Management (ERM) Pada Perusahaan. Industrial Engineering Online Journal, 5(2012), 4.

Suhendra, E. S., Oswari, T., \& Setiawan, S. (2013). Peran Business Continuity Plan dan Contingency Plan Dalam Meminimalisir Risiko Teknologi Informasi pada Industri Asuransi. Jurnal Asuransi Dan Manajemen Risiko, 1(1), 42-52.

Yap, P. (2017). Panduan praktis manajemen resiko perusahan. Growing publishing. 